internet leaving residents uncertain and anxious. Clear and easy to understand safety guidelines should be made in order to prevent anxiety among residents.

Methods A questionnaire survey was conducted of mothers with 1-3 years old and junior high school students (15 years old) in Hiroshima. Junior high school students were included as they will be play an important role in future societies and their mothers showed high levels of anxiety regarding this issue.

Results 75 questionnaires were collected from mothers and 79 questionnaires were collected from junior high school students. 66 mothers answered "I was anxious about radiation", 67 answered "I am worried about radiation from food". Interestingly, 16 said "I know where I can acquire information about radiation" and 2 said "I know the limit of the annual dose of radioactivity". 65 Students answered "I am anxious about radiation" and "I am worried about radiation from food". 6 answered, "I know where I can acquire information about radiation".

Conclusions Although neither mothers nor students worried about the health effects of radiation, knowledge was insufficient. If a nuclear accident happens residents' confusion will occur in the same way as it did following the Fukushima accident. The goal of safety guidance considered areas such as, residents have a clear understanding of radiation and know the information source is reliable in helping them make decisions. Health educators provided a simple method to measure radiation in the air, soil, water and foods etc. and clarify the normal radiation dose as it relates to Sievert and Becquerel. Publication of clear, reliable information is essential.

\section{TRAINING ON SAFETY ASSESSMENT AND MANAGEMENT FOR NEW AND INNOVATIVE CHILDREN'S PRODUCTS}

${ }^{1}$ Karina Pernías, ${ }^{1}$ Mari Cruz Arenas, ${ }^{1}$ Mari Carmen Hita, ${ }^{2}$ Dario Gregori, ${ }^{2}$ Giulia Lorenzoni, ${ }^{3}$ Helena Menezes, ${ }^{4}$ Pedro A Pernías. ${ }^{1}$ AIJU Technological Institute for Children'S Products and Leisure, Spain; ${ }^{2}$ Unit of Biostatistics, Epidemiology and Public Health, Department of Cardiac, Thoracic and Vascular Sciences, University of Padua, Italy; ${ }^{3}$ ANEC, the European Consumer Voice in Standardisation, Belgium; ${ }^{4}$ Universidad De Alicante, Departamento De Lenguajes Y Sistemas Informáticos, Spain

\subsection{6/injuryprev-2016-042156.753}

Background The children's products industry is forced to innovate continuously in order to maintain the business activity and meet the highest safety requirements, taking into account the special vulnerability of children as consumers. The SMEs which stand for $95 \%$ of total of this industry lack of resources and knowledge to assess the safety of their new products, which undermines their competitiveness. Similarly, consumer associations are the other weak stakeholder. According to the Regulation of the European Parliament and the Council on a Consumer Programme 2014-2020, one of the main issues to be addressed is the insufficient capacity of consumer organisations, especially the lack of resources and specialists, in the new Member States in particular.

Objective To develop and implement an innovative Open Educational Resource using ICT-based methodologies in order to provide training on safety assessment and management for new and innovative children's products customised to the needs of the staff working in the industry, consumer organisations and other stakeholders.

Results The result has been an online course with unlimited participation and free and open access via the Internet, commonly known as MOOC (Massive Open Online Course), on children's product safety. Its pedagogical design is focused on five key areas: learning, activities, resources, interactivity and assessment. It covers subjects such as the legal framework for children's products, risk analysis and epidemiology of the injuries related to products used by children.

Conclusions In addition to training, this MOOC has also served as a platform to exchange experience and raise awareness of the importance of safety products for children among the key stakeholders (consumers, industry and other stakeholders). MOOCs aimed at specific interest groups actively involved in product safety can become an effective tool to prevent unintentional injuries that arise from the use of products.

\section{FARM MAPPING TO ASSIST, PROTECT, AND PREPARE EMERGENCY RESPONDERS (FARM MAPPER)}

${ }^{1}$ Matthew Keifer, ${ }^{1}$ Bryan Weichelt, ${ }^{2}$ Gerald Minor, ${ }^{1}$ Iris Reyes, ${ }^{1}$ Casper Bendixsen. ${ }^{1}$ National Farm Medicine Centre, Marshfield Clinic Research Foundation, Marshfield, WI, USA, 2Pittsville Fire Department, Pittsville, WI, USA

\subsection{6/injuryprev-2016-042156.754}

Background Farm Mapping to Assist, Protect and Prepare Emergency Responders (Farm MAPPER) is an interactive web-based tool developed by the NFMC that provides emergency responders onsite information about hazards, resources and physical layouts of agricultural operations. Emergency responders generally do not have right of entry to private farms to map them for future emergencies. Farm MAPPER provides a palate of icons representing items important in emergency events such hazards, access points, water sources, etc., even information on special needs farm residents.

Methods The system was developed to allow a farmer to drag and drops icons on an overhead farm map using their computer. Through Farm MAPPER this information is accessible to emergency responders in the fire station, in-route by web connected device, or onsite using QR codes located on post box posts. This knowledge assists responders to efficiently and safely respond to on farm emergencies. MAPPER presently displays icons on Bing maps in an overhead bird's eye view of the farm.

Results The team developed and tested the prototype Farm MAPPER application with local farmers and conducted mock response with the Pittsville fire department using the MAPPER on a volunteer farms. Feedback was received from both groups. Farmers found it easy to use and expressed willingness to map their farms for the benefit of the emergency responders who might use the application. Emergency responders who participated in the mock responses found the application helpful in quickly locating the items that they needed to avoid or employ for their safety and response efficiency. They suggested modifications to the application which have since been incorporated.

Conclusions The system was developed to handle geographic diversity, and will be available for worldwide adoption. The team is currently seeking collaborative opportunities to further expand the project reach beyond central Wisconsin.

\section{HOW COULD ROAD SAFETY FUNDING BE EFFECTIVE?}

Arumdyah Widiati, Harry Evdorides. University of Birmingham, United Kingdom 
Background Limited budget in road safety projects generate a need to seek alternative funding for road safety with such mechanism which enable to achieve expected outcomes of road safety programmes without giving additional costs to government and tax payers.

Methods The research strategy is exploratory of a number of documents which related with road safety programmes, road financing, road safety financing, and social investments.

Results Managing funding in road safety using business-like approach rather than a government's social responsibility is considered as second generation of road funds (Robinson, 2008; Brushett, 2005). There could be commercial style road safety organisation/council/committee with strong public support for better road safety management and affordable road financing (Heggie, 2003). Road safety could be improve significantly if the interventions are carried out since preventive area. Preventive area is mostly seen as a public good. To make preventive area attractive to private sectors is to see preventive area as a merit good. The interventions are intended to improve safety level in an area of high social need and supported by evidence of efficacy. Impacts of interventions could be measured accurately. There is a saving, particularly for government, because of lower cost of the interventions and transactions.

Conclusions The effective funding for road safety is affected by timing of the interventions. Interventions which are conducted at prevention stage will give great impacts, comparing with other stage of road safety. Thus, funding which intended for this stage will give effective results. Beside of timing, funding mechanism should consider involvement of private sectors with outcome orientation.

\section{SAFETY MANAGEMENT IN SEAPORTS AND LOGISTIC CHAIN AND CONTAINER GASES AS AN OCCUPATIONAL SAFETY RISK}

Anne E Suominen, Sari Nyroos, Johanna Yliskylä-Peuralahti. University of Turku, Brahea Centre/Centre for Maritime Studies, Finland

10.1136/injuryprev-2016-042156.756

Background Occupational safety management includes awareness and prevention of risky situations, and maintenance of safe working environment. From an occupational safety perspective a seaport contains several critical interfaces because it is a shared workplace where employees represent many different organisations. An occupational safety risk in seaports and logistics operations is fumigants used in goods transported in containers. Reports of health impairments suffered among persons who have opened fumigated containers are reported from several countries. Objective The use of fumigants is an appropriate way to protect goods during transport and storage. Problems arise when transport documents do not make any record of fumigation, the containers are not labelled with warnings, and the persons handling the containers are unaware of the health risks. It is thus critical to raise awareness of the health risks of fumigation and create preventive measures.

Results In our recent collaborative networks ("Work safety culture - port as a communal workplace", "National operation model and work safety protocol for prevention of container gas risks", "Cargo securing working group") we have contributed to the aims of increasing awareness of occupational safety risks at seaports and the importance of shared safety culture by producing easy-to-access learning material and occupational safety guidelines; by inviting different authorities and stakeholder organisations to collaborative workshops to discuss the risks, prevention methods and best practices; and by enhancing international collaboration and information sharing.

Conclusions Sharing information about fumigation and cargo securing risks, and creation of a shared safety culture in collaboration between the different organisations that are involved in handling containers and the goods they contain are critical issues for safety in logistic operations.

\section{CONSENCUS AND CONFLICT MODELS IN HEALTH POLICY MAKING}

Bjarne Jansson. Karolinska Institutet, Department of Public Health Sciences, KI Campus, 17176

\subsection{6/injuryprev-2016-042156.757}

Implementation of the WHO Safe Community Program at local level includes an equity approach. Of interest is therefore, how well typologies on community organisation consider the needs for vulnerable and deprived groups in the community. Several models have been developed and implemented. Newer refined models have to consider problems in a multicultural context to a greater extent. Power, empowerment and critical consciousness are central concepts in community organising. Top-down models does not fully serve the interest of safety among deprived and expelled groups. One way is to make conflicts of interest much more transparent. Instead of consencus models a model based on Alinsky's conflict model "social action" could better challenge the conflicts of interest in the community.

\section{SYSTEMATIC SAFETY AND SECURITY RISK MANAGEMENT ON FARMS}

Jarkko Leppälä. Natural Resources Institute Finland (Luke)

\subsection{6/injuryprev-2016-042156.758}

Background The problems and risks are diverse in farming, which threaten safety and security on farms. Currently, there is little information how farm safety and security management is integrated into management on farms. The objective in this $\mathrm{PhD}$ study was to increase the understanding of systematic safety and security risk management applied to farms. Special attention was paid to the usability of risk management, the effectiveness of safety and security risk management, and the sustainability management on farms. Farm business security risks are risks, which threat the business continuity and sustainability on farms. These farm security risks include food production safety risks like human and animal diseases, farm economic crisis, water pollution and eutrophication caused by farming, asset risks like fire accidents, water and energy interruptions and farmers' serious occupational health problems all have exacerbated the special importance of risk management on farms. More information is needed on farm business continuity and supporting farms in systematic risk management as a holistic and practical manner. This dissertation presents new tools and applications for systematic risk management on farms.

Methods The study was a mixed method research. Systematic review of the literature, two surveys and case studies were conducted to identify safety and security risk management approaches in agriculture. Risk management aspects of a national 